\title{
Comparison of DNA and RNA quantification methods suitable for parameter estimation
}

in metabolic modeling of microorganisms

Marjan De Mey ${ }^{1}$, Gaspard Lequeux ${ }^{2}$, Jo Maertens ${ }^{2}$, Sofie De Maeseneire ${ }^{1}$, Wim Soetaert ${ }^{1}$ and Erick Vandamme ${ }^{1}$

${ }^{1}$ Ghent University, Laboratory of Industrial Microbiology and Biocatalysis, Department of Biochemical and Microbial Technology, Faculty of Bioscience Engineering, Coupure links 653, B-9000 Ghent, Belgium

${ }^{2}$ Ghent University, BIOMATH, Department of Applied Mathematics, Biometrics and Process Control, Faculty of Bioscience Engineering, Coupure links 653, B-9000 Ghent, Belgium

Running title: Quantification of nucleic acids

Subdivision: DNA Recombination Techniques and Nucleic Acids

Correspondence address: Marjan De Mey

Laboratory of Industrial Microbiology and Biocatalysis

Department of Biochemical and Microbial Technology

Faculty of Bioscience Engineering

Ghent University

Coupure links 653

B-9000 Gent

Tel.: +32-9-264-60-28

Fax: +32-9-264-62-31

Marjan.DeMey@UGent.be

http://www.limab.UGent.be 


\begin{abstract}
Recent developments in cellular and molecular biology require the accurate quantification of DNA and RNA in large numbers of samples at a sensitivity that enables determination on small quantities. Five current methods for nucleic acid quantification have been compared: 1) UV absorbance spectroscopy at 260nm, 2) Colorimetric reaction with the orcinol reagent, 3) Colorimetric reaction based on diphenylamine, 4) Fluorescence detection with reagent Hoechst 33258 and 5) Fluorescence detection with thiazole orange reagent. Genomic DNA of three different microbial species (with widely different G+C content) was used as well as two different types of yeast RNA and a mixture of equal quantities of DNA and RNA.

We can conclude that for nucleic acid quantification a standard curve with DNA of the microbial strain under study is the best reference. Fluorescence detection with reagent Hoechst $33258{ }^{\circledR}$ is a sensitive and precise method for DNA quantification if the G+C content is lower than $50 \%$. In addition this method allows quantification of very low levels of DNA (ng-scale). Moreover, the samples can be crude cell extracts. Also UV absorbance at 260nm and fluorescence detection with thiazole orange reagent are sensitive methods for nucleic acid detection, but only if purified nucleic acids have to be measured.
\end{abstract}

Keywords: nucleic acid quantification, spectroscopy, fluoroscopy, metabolic modeling 


\section{Introduction}

Whereas in the past the genetic potential of a microbial strain was improved by the iterative process of random mutagenesis and screening, the advent of recombinant DNA techniques and functional genomics made a goal-oriented approach for genetic modification possible (Metabolic Engineering) [1]. However, in most cases the construction of a producer strain did not turn out to be as straightforward as was initially presumed. Indeed, in complex metabolic networks, it is often a difficult task to ad hoc predict the impact, both qualitatively and quantitatively, of a genetic intervention [2]. Moreover, as the focus in metabolic engineering is shifting from massive overexpression and inactivation of genes towards the fine tuning of gene expression $[3,4]$, the need for a reliable, quantitative predictor, i.e. a model, is rapidly growing. Based on a given metabolic model, different computational tools for simulation, data evaluation, system analysis, prediction, design and optimization have been developed [5]. A central element of metabolic models is biomass, mainly composed of proteins, lipids, DNA and RNA. The accurate quantification of DNA and RNA for large numbers of samples at the highest possible sensitivity is required in order to obtain accurate data for the parameter estimation of those models.

A wide variety of methods have been used to quantify both RNA and DNA and assumptions have been made of both steady state and dynamic metabolic modelling. For example, Neidhardt and Umbarger [6] considered the ratio of the components of biomass of Escherichia coli to be constant. Several metabolic models are based on this assumption [712], where nucleic acids determination was based upon both UV absorbance spectroscopy at 260nm and the colorimetric diphenylamine reaction. In contrast, Pramanik and Keasling [13], presented a stoichiometric model of $E$. coli in which the ratio of biomass compounds is growth-rate dependent using the empirical formula described by Churchward et al. [14, 15]. 
Others [16-18] follow this assumption but DNA and RNA levels were determined using UV absorbance at $260 \mathrm{~nm}$.

The applied methods to quantify nucleic acids can be classified based on their detection principle namely spectrophotometric and fluorometric. In this study, we have assessed the performance of five nucleic acid quantification methods: 1) UV absorbance spectroscopy at $260 \mathrm{~nm}$ [19-21]; 2) colorimetric reaction of orcinol with the carbohydrate moiety of the nucleic acid [22-24]; 3) colorimetric reaction of deoxyribose sugar with diphenylamine in a mixture of acetic acid and sulphuric acid [19, 25-30]; 4) fluorescence detection after nonintercalatively binding of Hoechst 33258 with high specificity to double-stranded DNA [19, 31-33] and 5) fluorescence detection after complexation of thiazole orange with nucleic acids $[31,34]$. We have used genomic DNA of three different bacterial species (with different G+C content): gDNA from Clostridium perfringens (DNA_C, 26.5\%GC), gDNA from Escherichia coli (DNA_E, 50\%GC) and gDNA from Micrococcus luteus (DNA_M, 72\%GC). We also used two different types of yeast RNA: RNA type III from Saccharomyces cerevisiae (RNA_S) and RNA type VI from Torula yeast (RNA_T) and a mixture of equal quantities of DNA_E and RNA_S (DNA_RNA) to investigate the interference of DNA and RNA in the different methods.

\section{Materials and methods}

\subsection{Chemicals and solutions}

Tris, diphenylamine, Hoechst $33258^{\circledR}$ reagent, $\mathrm{HCl}, \mathrm{H}_{2} \mathrm{SO}_{4}$, thiazole orange reagent and glacial acetic acid were obtained from Sigma (Belgium); $\mathrm{NaCl}, \mathrm{CaCl}_{2}$, ethanol, $\mathrm{HClO}_{4}$ and 
$\mathrm{FeCl}_{3} \cdot 6 \mathrm{H}_{2} \mathrm{O}$ from VWR (Belgium). EDTA and acetaldehyde were obtained from Across (Belgium).

\subsection{Nucleic acid analysis}

\subsubsection{Nucleic acid standards}

Genomic DNA of five different species with varying $\mathrm{G}+\mathrm{C}$ content: gDNA of Clostridium perfringens type XII (DNA_C, 26.5\%GC), gDNA of Escherichia coli type VIII (DNA_E, 50\%GC), gDNA of Micrococcus luteus type XI (DNA_M, 72\%GC), gDNA of Calf thymus type IV (42\%GC) and gDNA of herring testes type XIV (43\%GC), two different types of RNA: RNA type III from Saccharomyces cerevisiae (RNA_S) and RNA type VI from Torula yeast (RNA_T) and a mixture of equal quantities of DNA_E and RNA_S (DNA_RNA) were used. All nucleic acids were purchased from Sigma (Belgium). EB-buffer (10mM Tris-HCl pH8.5) was used as solvent.

\subsubsection{UV absorbance spectroscopy at 260nm}

Nucleic acid measurements were performed as described by Sambrook and Russell [20]. Absorbance data $\left(\mathrm{A}=\log \mathrm{I} / \mathrm{I}_{0}\right)$ were collected using a UVIKOM 922 (BRS, Belgium) spectrophotometer. The absorption of DNA and RNA is maximal at $260 \mathrm{~nm}$. The extinction coefficients of nucleic acids are the sum of the extinction of each of their constituent nucleotides. For large molecules however, where it is impractical or impossible to sum up the coefficients of all nucleotides, an average extinction coefficient is used. According to Sambrook and Russell [20], for double-stranded DNA, the average extinction coefficient is 50 $(\mu \mathrm{g} / \mathrm{ml})^{-1} \mathrm{~cm}^{-1}$; for single stranded DNA or RNA the average coefficient is $38(\mu \mathrm{g} / \mathrm{ml})^{-1} \mathrm{~cm}^{-1}$. Also, for single-stranded DNA and RNA the values 37 and $40\left(\mu \mathrm{g} / \mathrm{ml}^{-1} \mathrm{~cm}^{-1}\right.$ are found, respectively. Thus, using a 1cm length path, $1 \mathrm{~A}_{260}$ unit equals $50 \mu \mathrm{g} / \mathrm{ml}$ double-stranded DNA or $38 \mu \mathrm{g} / \mathrm{ml}$ single-stranded DNA or RNA. 


\subsubsection{Colorimetric reaction with orcinol}

The measurements were performed as described by Endo [23] with some minor modifications to simplify the procedure. $0.5 \mathrm{ml}$ sample was added to $0.5 \mathrm{ml}$ orcinol solution $(0.1 \%$ orcinol and $0.1 \% \mathrm{FeCl}_{3} \cdot 6 \mathrm{H}_{2} \mathrm{O}$ in concentrated $\mathrm{HCl}$ ) in double. The 2 Eppendorf tubes were incubated at $100^{\circ} \mathrm{C}$ for $2 \mathrm{~min}$ to quantify DNA and $15 \mathrm{~min}$ to quantify all nucleotides (DNA+RNA), respectively, followed by immediate cooling under running water and putting on ice to stop the reaction. After cooling the Eppendorf tubes, taken out at 2min, were allowed to incubate at $37^{\circ} \mathrm{C}$ for $2 \mathrm{~h}$ and the absorbance at $600 \mathrm{~nm}$ was measured using a UVIKOM 922 spectrophotometer. The absorbance of the solutions, taken out at $15 \mathrm{~min}$, was measured immediately after cooling. Blanks (EB-buffer) were included for both methodologies.

\subsubsection{Colorimetric reaction with diphenylamine}

The measurements were performed based on the Burton diphenylamine method [25]: 1ml of $4 \%$ diphenylamine in glacial acetic acid was added to $0.5 \mathrm{ml}$ test volume solved in $1 \mathrm{M} \mathrm{H}_{2} \mathrm{SO}_{4}$. The reaction mixture was kept overnight $(16 \mathrm{~h})$ at $30^{\circ} \mathrm{C}$. Two different absorbance wavelengths were tested, encoded DPA_1 and DPA_2. In method DPA_1, the colouring was measured by reading the absorbance at $600 \mathrm{~nm}$ as described by Dische [26]. In method DPA_2, the resulting blue colouring was measured as the absorbance difference between 595nm and 700nm as described by Giles and Myers [28]. They reported that measuring the 595nm-700nm absorbance difference, eliminates the error due to turbidity generated by precipitation of impurities during incubation, as the absorbance of these impurities is the same for both wavelengths. EB-buffer was used as a blank.

\subsubsection{Fluorescence detection with Hoechst $33258^{\circledR}$}

The nucleic acid determination was performed as described by Bachoon et al. [34] with some

modifications. Hoechst solution was fresh made by adding $4 \mathrm{ml}$ Hoechst $33258^{\circledR}(0.5 \mu \mathrm{g} / \mathrm{ml})$ to 
5ml 10x TNE buffer (1M NaCl, 10mM EDTA, 0.1M Tris-HCl pH7.4) and 41ml MiliQ- $\mathrm{H}_{2} \mathrm{O}$. 0.5ml sample was added to $1 \mathrm{ml}$ Hoechst solution and a black 96-well microtiter-plate was filled with $100 \mu$ l Hoechst-sample mixture. As a blank 0.5ml EB-buffer was used. Different excitation wavelengths and emission wavelengths have been reported [20, 31, 32, 34, 35]. Three pairs of excitation/emission wavelengths were used: 360nm excitation/460nm emission (H1), 360nm excitation/ 465nm emission (H2) and 356nm excitation/ 458nm emission (H3). The measurements were performed with a Spectramax Gemini XS (Molecular Devices, Belgium).

\subsubsection{Fluorescence detection with thiazole orange (TO)}

The measurements were performed as described by Berdalet and Dortch [31]. 0.5ml sample (in EB-buffer) was added to $0.55 \mu \mathrm{M}$ thiazole orange solution (in ethanol) and $1.45 \mathrm{ml}$ TrisCa $^{2+}$ buffer (132.4mg/l CaCl $2,5.84 \mathrm{~g} / \mathrm{l} \mathrm{NaCl}, 12.11 \mathrm{~g} / \mathrm{l}$ Tris-HCl pH 7.5). Black 96-well microtiter-plates were filled with $100 \mu \mathrm{l}$ mixture and readings were carried out at $511 \mathrm{~nm}$ excitation wavelength and 533nm emission wavelength with auto cut off on a Spectramax Gemini XS.

\subsubsection{Statistical analysis}

The different methods can not be compared directly, as they do not give the same response and are not applicable to the same range of concentrations. Most methods work well in the range of $100 \mu \mathrm{g} / \mathrm{l}$ nucleic acid, while the Hoechst methods are more sensitive and measure in the range of $1 \mathrm{ng} / \mathrm{l}$ nucleotides. Therefore, for each method the concentrations and responses (absorbance or fluorescence) were rescaled between zero and one. The statistical package $\mathrm{R}$ [36] was used to perform the linear regression on those rescaled data and to calculate the $95 \%$ confidence intervals. 
The quality of the different nucleic acid quantification methods is mainly determined by the slope of the response variable (absorbance or fluorescence) to concentration. The lower this slope, the less sensitive the method. However, the slope is not the only important parameter. Also the variance on the slopes should be taken into account. Therefore each slope is divided by its variance. This value represents the reliability of the method.

After performing the linear regression, the residuals were calculated. A boxplot of these residuals was made using the statistical package $\mathrm{R}$. This boxplot enables one to compare the different quantification methods for the different nucleotides.

\section{Results and discussion}

\subsection{Sensitivity of the methods}

Varying concentrations of the different nucleic acids were measured using an average extinction coefficient (50 or 38) as described above. For each DNA/RNA species a linear regression was performed using the statistical package R (data not shown). From this linear regression the average extinction coefficient was calculated. Table 1 illustrates that the "standard" of an average extinction coefficient of 50 is only valid for Escherichia coli gDNA (50\%GC). As to the other bacterial species, this reference does not hold. It is clear that different species give different average extinction coefficients. This is due to the differing $\mathrm{G}+\mathrm{C}$ content and the nucleotide sequence structure. Consequently, it is essential to generate a standard curve for each gDNA species under study, in order to produce highly accurate data for metabolic modelling. DNA from calf thymus or from herring testes should not be used as standard although this has been reported in literature [37].

Table 1 
In the lower part of figure 1, the slope of the linear regression for each combination of method and type of nucleic acid is depicted. This is a measure for the sensitivity of a method to different nucleic acids. However, to compare the methods in a statistically way, the slope was divided by their variance. This measure is depicted in the upper part of figure 1 .

\section{Figure 1}

As reported in the literature [20,31, 32, 34, 35], the diphenylamine and Hoechst $33258^{\circledR}$ based methods are only able to detect DNA, whereas the other tested protocols can also be used to quantify RNA.

For all methods, one can thus conclude that it is preferable to use a standard curve on the basis of nucleic acids of the microbial strain under study.

Although UV absorbance at 260nm is one of the most popular methods for nucleic acid quantification, it requires extremely pure samples of nucleic acids, due to the interfering absorbance of contaminating molecules. As can be seen in figure 1 the method is not really reliable for DNA/RNA mixture. For the other nucleic acid types, the method is quite sensitive and reliable.

The sensitivities of the orcinol method are significantly differing for the distinct nucleic acids, except for DNA_C and DNA_M. Thus, it seems better to use the nucleic acid from the species under study as a reference to compute a standard curve. The reliability of RNA_T, RNA_S and DNA_RNA are smaller than for the other nucleic acid types.

It can be concluded that there is no significant difference between the two procedures for the DPA method. However, this method can not be used for RNA quantification. Moreover there is a significant difference between DNA_C and the other two DNA's (DNA_E and DNA_M). 
DNA_E and DNA_M are not significantly different in sensitivity, but DNA_E shows a higher reliability. Although, it is better to use as standard the nucleic acid from the species under study, for DNA_E and DNA_M, these standards can be interchanged.

From three excitation/emission wavelengths pairs tested in the Hoechst protocol, the third one (H3) is the most reliable. As reported in the literature [20], the fluorescence intensity increases proportionally with the A+T content of the DNA. For gDNA with a $\mathrm{G}+\mathrm{C}$ content lower than 50, the sensitivity of the method increases but the reliability decreases. The results confirm that Hoechst $33258^{\circledR}$ preferentially interacts with the A/T rich regions of the DNA helix; the $\log _{10}$ of the intensity of fluorescence increases in proportion with the $\mathrm{A}+\mathrm{T}$ content of the DNA. Because Hoechst $33258^{\circledR}$ has little affinity for proteins or rRNA, cell lysates or purified preparations of DNA can be used for DNA quantification. This method allows the detection of nanogram quantities of DNA.

In contrast with Hoechst $33258^{\circledR}$, it can be concluded that for fluorescence detection with thiazole orange, the intensity of fluorescence of gDNA increases with the $\mathrm{G}+\mathrm{C}$ content of the gDNA. Hansen et al. [38] and Jacobsen et al. [39] have reported that the homodimeric thiazole orange (TOTO) binding is sequence selective at 5'-CTAG-3' and 5'- CCGG-3' sites. This might explain the increase in fluorescence intensity with the $\mathrm{G}+\mathrm{C}$ content. This method is less sensitive for RNA.

\subsection{Comparison of the different methods}

To be able to compare the different quantification methods for the different nucleotides, residuals were calculated after performing a linear regression. The boxplot of these residuals can be found in figure 2. Each entry represents a nucleic acid species/method combination. RNA and DNA/RNA mixtures for the methods DPA and Hoechst $33258^{\circledR}$ were not included in the figure as they are not suitable for RNA quantification. 
Figure 2

Although the colour reaction with diphenylamine has been studied and modified many times [19, 25, 27-30], figure 2 shows clearly that it is not a precise method for DNA quantification (high spread of the residuals in figure 2).

Whereas the colorimetric reaction of orcinol with the sugar component is described as a widely used method for the estimation of RNA, D-ribose and other pentoses [22, 23], this method is only precise for DNA quantification, not for RNA and DNA/RNA mixtures. This might be explained by the reaction mechanism described by Brückner [22]. The colour development due to the reaction of carbohydrates and mono-or poly-hydric phenols heated in the presence of strong mineral acids is usually attributed to the formation of furfurals from pentoses which condense with phenolic reagents to give coloured products.

As can be seen in figure 2, the Hoechst $33258^{\circledR}$ method becomes more and more accurate for DNA quantification when the G+C content decreases. However DNA_C (26.5\%GC) shows more variability.

Both UV absorbance spectroscopy at 260nm and fluorescence detection with thiazole orange are good methods for nucleic acid quantification. However, for DNA/RNA mixtures, UV absorbance at 260 shows more variability and is thus less suitable.

\section{Conclusion}

Recent developments in cellular and molecular biology require the accurate quantification of DNA and RNA in large numbers of samples at a sensitivity that enables determination on small quantities. In this study, five state of the art methods for nucleic acid quantification have been evaluated using different bacterial gDNA and yeast RNA types. It was found that for nucleic acid quantification, a standard curve with DNA from the species being assayed is the best reference. Fluorescence detection with Hoechst $33258^{\circledR}$ is a sensitive and precise method 
for DNA quantification provided that the $\mathrm{G}+\mathrm{C}$ content is lower than $50 \%$. In this case, the method allows quantification of very low levels of DNA (ng-scale). Moreover, even crude cell extracts can be used as sample. On the other hand, every nucleic acid species can be quantified with UV absorbance at $260 \mathrm{~nm}$ or fluorescence detection with thiazole orange reagent provided that the samples are purified.

\section{Acknowledgements}

The authors wish to thank the Institute for the Promotion of Innovation through Science and Technology in Flanders (IWT-Vlaanderen) for financial support in the framework of a Ph.D grant and the Fund for Scientific Research-Flanders (FWO-Vlaanderen) for the support through the FWO-project G.0184.04. The $3^{\text {rd }}$ author is research assistant of the Fund for Scientific Research-Flanders. The authors also wish to thank Katja Van Nieuland for practical help and Karl Rumbold for inspiring discussions.

\section{References}

[1] J. E. Bailey, Toward a science of metabolic engineering, Science 252 (1991) 16681675.

[2] J. E. Bailey, A. R. Sburlati, V. Hatzimanikatis, K. Lee, W. A. Renner, P. S. Tsai, Inverse metabolic engineering: a strategy for directed genetic engineering of useful phenotypes, Biotechnol. Bioeng. 52 (1996) 109-121.

[3] H. Alper, C. Fischer, E. Nevoigt, G. Stephanopoulos, Tuning genetic control through promoter engineering, Proc. Natl. Acad. Sci. U.S.A 102 (2005) 12678-12683. 
[4] C. Fischer, H. Alper, E. Nevoigt, K. Jensen, G. Stephanopoulos, Response to Hammer et al.: Tuning genetic control - importance of thorough promoter characterization versus generating promoter diversity, Trends Biotechnol. (2006).

[5] W. Wiechert, Modeling and simulation: tools for metabolic engineering, J. Biotechnol. 94 (2002) 37-63.

[6] F. C. Neidhardt, H. E. Umbarger (1996) in Escherichia coli and Salmonella (F. C. Neidhardt, R. Curtiss, J. L. Ingraham, E. C. C. Lin, K. B. Low, B. Magasanik, W. S. Reznikoff, M. Riley, M. Schaechter, H. E. Umbarger, Eds.), ASM press, Washington.

[7] J. S. Edwards, B. O. Palsson, The Escherichia coli MG1655 in silico metabolic genotype: its definition, characteristics, and capabilities, Proc. Natl. Acad. Sci. U S A 97 (2000) 5528-5533.

[8] S. H. Hong, S. Y. Moon, S. Y. Lee, Prediction of maximum yields of metabolites and optimal pathways for their production by metabolic flux analysis, J. Microbiol. Biotechn. 13 (2003) 571-577.

[9] S. Y. Lee, S. H. Hong, S. Y. Moon, In silico metabolic pathway analysis and design: succinic acid production by metabolically engineered Escherichia coli as an example, Genome Informatics 13 (2002) 214-223.

[10] S. M. See, J. P. Dean, G. Bervakos, On the topological features of optimal metabolic pathway regimes, Appl. Biochem. Biotechnol. 60 (1996) 251-301.

[11] A. Varma, B. O. Palsson, Stoichiometric flux balance models quantitatively predict growth and metabolic by-product secretion in wild-type Escherichia coli W3110, Appl. Environ. Microbiol. 60 (1994) 3724-3731.

[12] A. Varma, B. O. Palsson, Parametric sensitivity of stoichiometric flux balance models applied to wild-type Escherichia coli metabolism, Biotechnol. Bioeng. 45 (1995) 6979. 
[13] J. Pramanik, J. D. Keasling, Stochiometric model of Escherichia coli metabolism: incorporation of growth-rate dependent biomass composition and mechanistic energy requirements, Biotechnol. Bioeng. 56 (1997) 398-421.

[14] H. Bremer, P. P. Dennis (1996) in Escherichia coli and Salmonella (F. C. Neidhardt, R. Curtiss, J. L. Ingraham, E. C. C. Lin, K. B. Low, B. Magasanik, W. S. Reznikoff, M. Riley, M. Schaechter, H. E. Umbarger, Eds.), ASM press, Washington DC.

[15] R. Carlson, F. Srienc, Fundamental Escherichia coli biochemical pathways for biomass and energy production: identification of reactions, Biotechnol. Bioeng. 85 (2004) 1-13.

[16] M. Dauner, U. Sauer, Stoichiometric growth model for riboflavin-producing Bacillus subtilis, Biotechnol. Bioeng. 76 (2001) 132-143.

[17] M. Dauner, T. Storni, U. Sauer, Bacillus subtilus metabolism and energetics in carbonlimited and excess-carbon chemostat culture, J. Bacteriol. 183 (2001) 7308-7317.

[18] M. Emmerling, M. Dauner, A. Ponti, J. Fiaux, M. Hochuli, T. Szyperski, K. Wüthrich, J. E. Bailey, U. Sauer, Metabolic flux responses to pyruvate kinase knockout in Escherichia coli, J. Bacteriol. 184 (2002) 152-164.

[19] A. Dell'Anno, M. Fabiano, G. C. A. Duineveld, A. Kok, R. Danovaro, Nucleic acid (DNA, RNA) quantification and RNA/DNA ratio determination in marine sediments: Comparison of spectrophotometric, fluorometric, and high-performance liquid chromatography methods and estimation of detrital DNA, Appl. Environ. Microbiol. 64 (1998) 3238-3245.

[20] J. Sambrook, D. W. Russell (2001) Molecular cloning: a laboratory manual, Cold Spring Harbor Laboratory Press, Cold Spring Harbor, New York.

[21] O. Warburg, W. Christian, Isolierung und kristallisation des gärungsferments enolase, Biochem. Z. 310 (1942) 384-421. 
[22] J. Brückner, Estimation of monosaccharides by the orcinol-sulphuric acid reaction, Biochem. J. 60 (1955) 200-205.

[23] Y. Endo, A simultaneous estimation method of DNA and RNA by the orcinol reaction and a study on the reaction mechanism, J. Biochem. (Tokyo) 67 (1970) 629-33.

[24] M. Kamali, H. Manhouri, A modified orcinol reaction for RNA determination, Clin. Chem. 15 (1969) 390-2.

[25] K. Burton, Citation Classics - Study of conditions and mechanism of diphenylamine reaction for colorimetric estimation of deoxyribonucleic-acid, Current Contents 26 (1977) 315-323.

[26] Z. Dische, Über einige neue charakteristische Farbreaktionen der Thymonukleïnsäure und eine Mikromethode zur Bestimming derselben in tierischen Organen mit Hilfe dieser Reaktionen, Mikrochemie 8 (1930) 4-32.

[27] G. J. Gendimenico, P. L. Bouquin, K. M. Tramposch, Diphenylamine-colorimetric method for DNA assay - A shortened procedure by incubating samples at $50^{\circ} \mathrm{C}$, Anal. Biochem. 173 (1988) 45-48.

[28] K. W. Giles, A. Myers, An improved diphenylamine method for the estimation of deoxyribonucleic acid, Nature 206 (1965) 93.

[29] M. Liebeskind, M. Dohmann, Improved method of activated-sludge biomass determination, Water Sci. Technol. 29 (1994) 7-13.

[30] C. T. Thompson, J. A. Dvorak, Quantitation of total DNA per cell in an exponentially growing-population using the diphenylamine reaction and flow-cytometry, Anal. Biochem. 177 (1989) 353-357.

[31] E. Berdalet, Q. Dortch, New double-staining technique for RNA and DNA measurement in marine-Phytoplankton, Mar. Ecol.-Prog. Ser. 73 (1991) 295-305. 
[32] L. Lamboursain, M. Jolicoeur, Determination of cell concentration in a plant cell suspension using a fluorescence microplate reader, Plant Cell Rep. 23 (2005) 665-672.

[33] S. A. Latt, J. C. Wohlleb, Optical studies of the interaction of 33258 Hoechst with DNA, chromatin, and metaphase chromosomes, Chromosoma 52 (1975) 297-316.

[34] D. S. Bachoon, E. Otero, R. E. Hodson, Effects of humic substances on fluorometric DNA quantification and DNA hybridization, J. Microbiol. Methods 47 (2001) 73-82.

[35] C. Labarca, K. Paigen, Simple, rapid, and Sensitive DNA assay procedure, Anal. Biochem. 102 (1980) 344-352.

[36] R. Gentleman, R. Ihaka (1997), The R Project for Statistical Computing, http://www.R-project.org.

[37] H. C. Lange, J. J. Heijnen, Statistical reconciliation of the elemental and molecular biomass composition of Saccharomyces cerevisiae, Biotechnol. Bioeng. 75 (2001) 334-344.

[38] L. F. Hansen, L. K. Jensen, J. P. Jacobsen, Bis-intercalation of a homodimeric thiazole orange dye in DNA in symmetrical pyrimidine-pyrimidine-purine-purine oligonucleotides, Nucleic Acids Res. 24 (1996) 859-867.

[39] J. P. Jacobsen, J. B. Pedersen, L. F. Hansen, D. E. Wemmer, Site-selective bisintercalation of a homodimeric thiazole orange-dye in DNA oligonucleotides, Nucleic Acids Res. 23 (1995) 753-760. 


\section{Figure legends}

\section{Figure 1}

The lower part (sensitivity) represents the slope of the concentration versus the response for each species of nucleic acid/method combination. For each method both the concentration and the response (absorbance or fluorescence) were rescaled between zero and one. Thus no method comparison is possible here. The error bars represent the 95\% confidence interval. In the upper part of the figure, each slope is divided by his standard deviation (reliability). This way, different methods can be compared.

\section{Figure 2}

Box plots for each nucleic acid/method combination after rescaling the response for each method between zero and one. RNA and RNA/DNA mixtures for the methods DPA and H33258 were not included because these methods can not quantify RNA.

\section{Table legends}

\section{Table 1}

The calculated average extinction coefficient divided by the theoretical average extinction coefficient $\left(50\left(\mu \mathrm{g} / \mathrm{ml}^{-1} \mathrm{~cm}^{-1}\right)\right.$ for gDNA from different species 


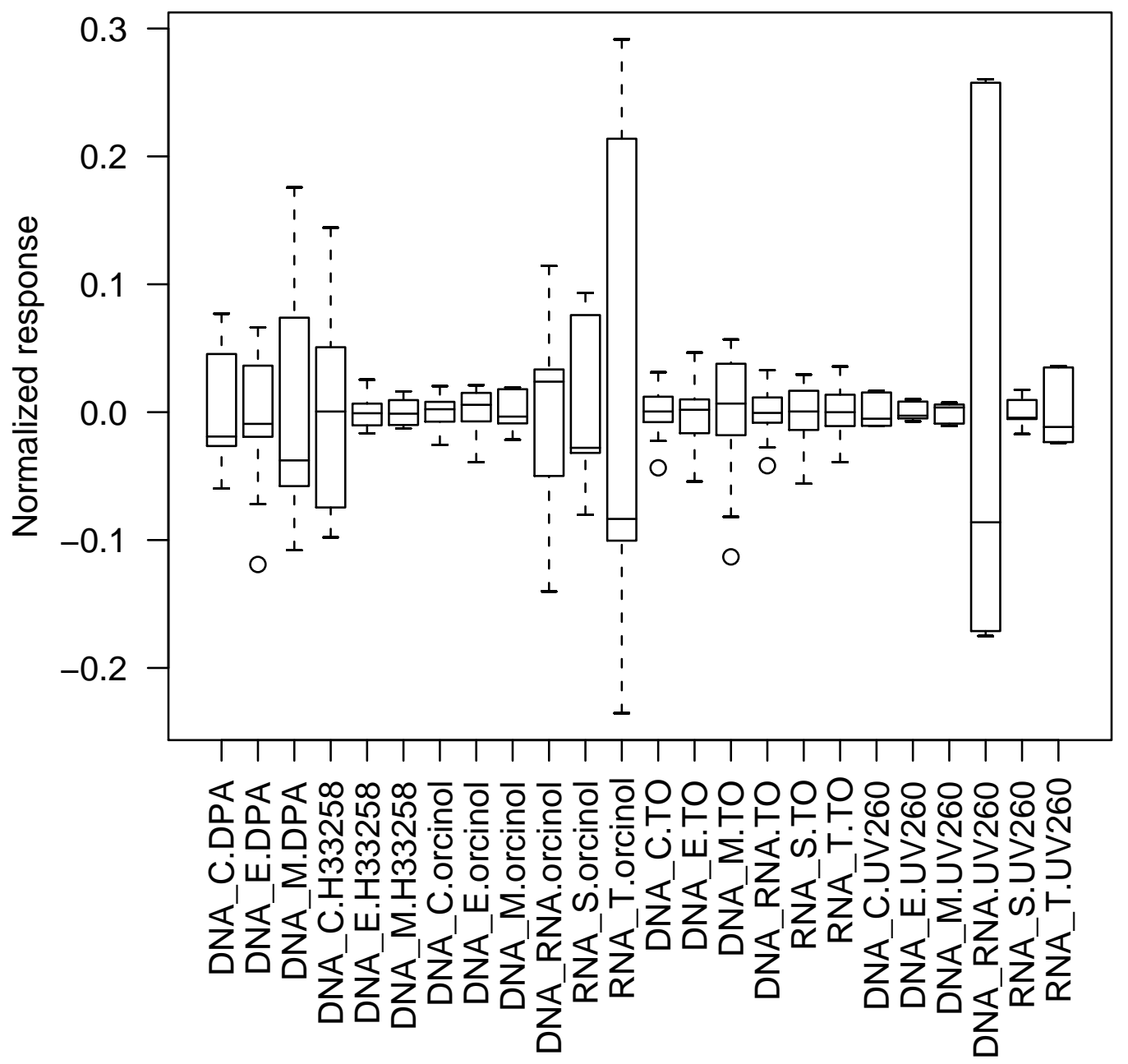




\section{Rate of the calculated and}

\section{Species}

\section{theoretical average}

St. Dev.

\section{extinction coefficient}

gDNA Clostridium perfringes

type XII

gDNA Eschericha coli

type VIII

gDNA Micrococcus luteus

type XI

gDNA Calf Thymus type IV

gDNA Herring Testes type XIV
1,5826

0,0796

0,9998

0,0092

1,5976

0,0514

1,0936

0,0072

1,029

0,0288 